\title{
Reduced transcription of the Smad4 gene during pulmonary carcinogenesis in idiopathic pulmonary fibrosis
}

\author{
KIYOSHI TAKENAKA ${ }^{1}$, AKIHIKO GEMMA ${ }^{1}$, AKINOBU YOSHIMURA ${ }^{1}$, YOKO HOSOYA ${ }^{1}$, MICHIYA NARA ${ }^{1}$, \\ YUKIO HOSOMI $^{1}$, TETSUYA OKANO ${ }^{1}$, SHINOBU KUNUGI ${ }^{4}$, KIYOSHI KOIZUMI ${ }^{3}$, YUH FUKUDA ${ }^{4}$, \\ KAZUTSUGU UEMATSU ${ }^{2}$, KAZUO SHIMIZU ${ }^{3}$ and SHOJI KUDOH ${ }^{1}$
}

\author{
Departments of ${ }^{1}$ Internal Medicine, Divisions of Pulmonary Medicine, Infectious Diseases and Oncology, ${ }^{2}$ Pathology, and \\ ${ }^{3}$ Surgery, Divisions of Endocrine, Cardiovascular and Thoracic Surgery, Nippon Medical School, Tokyo 113-8602; \\ ${ }^{4}$ Division of Pulmonary Medicine, Saitama Medical Center, Kamoda, Kawagoe-shi, Saitama 350-8550, Japan
}

Received April 16, 2008; Accepted September 30, 2008

DOI: $10.3892 / \mathrm{mmr} 00000064$

\begin{abstract}
Patients with idiopathic pulmonary fibrosis (IPF) have an increased risk of developing lung cancer. To identify key molecules involved in malignant transformation in IPF, we analyzed the expression profiles of lung and lung tumor tissue from patients with lung cancer and IPF (lung cancer/ IPF) using cDNA arrays and real-time quantitative reverse transcriptase-polymerase chain reaction (RT-PCR). Reduced expression of the Smad4 gene was identified in all eight tumor samples from the lung cancer/IPF patients using real-time RT-PCR. Expression levels of Smad4 were significantly lower in tumors from lung cancer/IPF patients than in those from lung cancer patients without IPF or in lung cancer cell lines ( $\mathrm{p}<0.01)$. Mutational analysis of TGF- $\beta$ type II receptor and Smad4 was performed using polymerase chain reaction-single strand conformation polymorphism (PCR-SSCP). The methylation status of the Smad4 promoter was analyzed using methylation-specific PCR with subsequent sequence analysis. No mutations were detected in the eight tumor samples, but hypermethylated regions were detected in the Smad4 promoter in two of the eight tumors with reduced Smad4 expression. Promoter reporter assays showed that the activity of the Smad4 promoter containing the sequence of the methylated region was significantly stronger than that of the Smad4 promoter with a deleted methylated region $(\mathrm{p}<0.002)$. Our findings indicate that the loss of the growth inhibitory response to TGF- $\beta$ signaling may be crucial in pulmonary carcinogensis or in the progression of lung cancer in IPF patients in whom
\end{abstract}

Correspondence to: Dr Akihiko Gemma, Department of Internal Medicine, Divisions of Pulmonary Medicine, Infectious Diseases and Oncology, Nippon Medical School, 1-1-5 Sendagi, Bunkyo-ku, Tokyo 113-8602, Japan

E-mail: agemma@nms.ac.jp

Key words: lung cancer, idiopathic pulmonary fibrosis, Smad4, hypermethylation, transforming growth factor $-\beta$
TGF- $\beta$ is overexpressed; hypermethylation of the Smad4 promoter region may be one mechanism by which this occurs. These findings are useful for the development of preventive measures or treatment for lung cancer patients with IPF.

\section{Introduction}

Idiopathic pulmonary fibrosis (IPF) is an interstitial lung disease of uncertain etiology. Patients with IPF have been shown to be 14.1 times more likely to develop lung cancer than the general population, and more than $10 \%$ of IPF patients die of lung cancer $(1,2)$. Currently, few IPF patients with lung cancer can be treated by surgery, radiotherapy and/ or chemotherapy due to pulmonary dysfunction or severe adverse effects. The development of new therapies is therefore essential. To clarify the mechanisms of pulmonary carcinogenesis in IPF, we previously analyzed microdissected tissues of the metaplasias and bronchiolar epithelia of IPF patients. Using polymerase chain reaction (PCR)-based microsatellite analysis, fluorescent in situ hybridization (FISH) and immunohistochemistry of the fragile histidine triad (FHIT) protein, we observed frequent allelic losses and reduced expression of the FHIT gene (3), and suggested that FHIT gene inactivation may be involved in tumorgenesis in patients with IPF.

To identify key molecules involved in malignant transformation in IPF patients, we analyzed the expression profiles of cancer-related genes in lung tumor and paired IPF tissue from patients with lung cancer and IPF (lung cancer/ IPF) using cDNA array analysis and real-time quantitative RT-PCR. It is often difficult to obtain fresh samples for expression analysis from patients with lung cancer/IPF, as only a small percentage undergo surgical resection. When we examined 64 lung cancer patients with IPF in our hospital, 14 (21.9\%) were undergoing surgery. Of the 14 , frozen lung cancer and tissues affected by IPF were available for expression analysis from eight patients. Real-time RT-PCR was used to confirm results obtained by cDNA array analysis, and the mechanism of transcriptional change was analyzed by mutational analysis, methylationspecific PCR and promoter reporter assays with or without the sequence including the methylated region. 


\section{Materials and methods}

Tissue samples, RNA and DNA extractions. Frozen lung cancer and IPF tissues from eight lung cancer/IPF patients were available for expression analysis. All patients provided written/ oral informed consent for the use of the tissues. All tissues were frozen in liquid nitrogen after surgery and stored at $-80^{\circ} \mathrm{C}$ until analysis. The lung cancers by histological type included four cases of squamous cell carcinomas, two of adenocarcinoma, one of small cell carcinoma and one of large cell carcinoma. All patients were male, ranging in age from 64 to 77 years. Using RT-PCR, we also analyzed Smad4 gene expression in four lung cancer (adenocarcinoma) patients without IPF and eight lung cancer cell lines: Lu65, A549, PC7, PC9 and PC14 (adenocarcinoma cell lines) and NCI-N231, NCI-H69 and Lu135 (small cell carcinoma cell lines). The Lu65 and Lu135 cell lines were provided by Y. Shimosato and T. Terasaki (National Cancer Center Research Institute, Tokyo, Japan). NCI-N231, A549 and NCI-H69 were obtained from the American Type Culture Collection (Rockville, MD). PC7, PC9 and PC14 were obtained from IBL (Gunma, Japan). RNA and genomic DNA were isolated from each sample using standard previously described protocols $(4,5)$.

cDNA array hybridization and analysis of hybridization signals. mRNA was isolated from total RNA by incubation with oligo-dT-magnetic beads (Toyobo Co., Osaka, Japan). The Gene Navigator cDNA Array System-Cancer Selected (Toyobo Co.) was used for cDNA analysis as previously reported (5). One hundred and seventy-seven species of human DNA fragments were spotted in duplicate on a filter. The genes on the filter included cancer-related genes, housekeeping genes and non-mammalian genes as negative controls. A list of the set of genes on the filter can be found at the site: (http://www.toyobo.co.jp/seihin/xr/product/genenavigator. html). To construct the probes, reverse transcription was performed using Reverse Transcriptase, ReverTra Ace (Toyobo Co.), a random 9mer (Toyobo Co.) as the primer and $5 \mu \mathrm{g}$ of polyA RNA. The probes were labeled with biotin by incorporation of biotin-16-deoxyuracil triphosphate (dUTP) during the synthesis of cDNA. The filters were pre-incubated in $20 \mathrm{ml}$ of PerfectHyb (Toyobo Co.) at $68^{\circ} \mathrm{C}$ for $30 \mathrm{~min}$. The biotin-labeled probes were denatured and added to the prehybridization solution. The filters were incubated overnight at $68^{\circ} \mathrm{C}$ in the hybridization mixture. After washing, specific signals on the filters were detected by the Imaging High Chemifluorescence Detection kit (Toyobo Co.). Vistra ECF substrate (AttoPhos) (Amersham Pharmacia Biotech, Uppsala, Sweden) was used as the chemifluorescence substrate. A chemifluorescence image of the filter was acquired by FluorImager (Amersham Pharmacia Biotech). Gene expression images were quantified by measuring the intensity of the signals using Imagene (BioDiscovery, Los Angeles, CA). Signal intensity among filters was compared using E-Gene Navigator Analysis (GeneticLab, Sapporo, Japan). The background threshold was set at a level 5-fold higher than the negative control. The signal intensities were normalized by comparing the expression of the housekeeping gene GAPDH (glyceraldehyde-3-phosphate dehydrogenase). A significant difference in gene expression between two examined tissue samples was defined as a $\geq 3$-fold difference in the signal intensity ratio.

Real-time quantitative RT-PCR. Quantitative PCR was performed using the ABI PRISM 7700 Sequence Detector (Perkin Elmer/Applied Biosystems, Foster City, CA). PCR primers and TaqMan fluorogenic probes were designed using the Primer Express software program (Perkin-Elmer/Applied Biosystems). Their sequences are shown in Table I. Using a random hexamer and ReverTra Ace- $\alpha, 1 \mu \mathrm{g}$ of each total RNA was reverse transcribed. A portion of the cDNA was used for quantitative PCR in a 50- $\mu 1$ volume using the designed primers, TaqMan probes and Master Mix (PCR buffer, $\mathrm{MgCl}_{2}$, dATP, dCTP, dGTP, dUTP, AmpErase UNG and AmpliTaq Gold DNA polymer-ase) (Perkin-Elmer/Applied Biosystems). The initial thermal cycle conditions were $50^{\circ} \mathrm{C}$ for $2 \mathrm{~min}$ and $95^{\circ} \mathrm{C}$ for $10 \mathrm{~min}$ as recommended by the manufacturer. The cycle conditions were $95^{\circ} \mathrm{C}$ for $15 \mathrm{sec}$ and $60^{\circ} \mathrm{C}$ for $1 \mathrm{~min}$, and the number of cycles was 40 . The RNA level of a gene was expressed as the ratio of the level of RNA of that gene to the level of GAPDH RNA in the sample.

Polymerase chain reaction-single strand conformation polymorphism analysis. Mutations in exons of the Smad4 and $T G F-\beta$ receptor type II (TGF- $\beta$ RII) genes were analyzed by polymerase chain reaction-single strand conformation polymorphism (PCR-SSCP). In each genomic DNA sample from the lung cancers, 11 exons of the Smad4 gene and two exons of the $T G F-\beta$ RII gene were amplified separately with the PCR primers as previously reported (6-8) (Table II). Mutation of the Smad4 promoter (9) was also analyzed using a primer pair as follows: forward 5'-TGCTCAGTGGCT TCTCG-3' and reverse 5'-TAGGGGAGAGCAGGAAG-3'. The PCR reaction tube mix contained 25 pmol of each primer labeled with fluorescein isothiocyanate (FITC), $2.5 \mathrm{mM}$ dNTPs, 1.25 units of Ex Taq DNA polymerase and 1X Ex Taq buffer (Takara, Tokyo, Japan) in a final reaction volume of $20 \mu 1$. The $20-\mu 1$ reaction mixture was placed in a DNA thermal cycler (PerkinElmer Cetus, Norwalk, CT) when the heating block reached $94^{\circ} \mathrm{C}$. PCR conditions for each set of primers were optimized. Standard denaturing and extension temperatures of 94 and $72^{\circ} \mathrm{C}$, respectively, were used. Annealing temperatures were $56^{\circ} \mathrm{C}$ for $\mathrm{Smad} 4$ analysis, and the number of cycles was 35 or 45 , respectively (6-8). FITC-labeled PCR products were denatured, cooled on ice and loaded on neutral $6 \%$ polyacrylamide gels with or without $5 \%$ (vol/vol) glycerol as described previously (4). After electrophoresis, the gels were analyzed with the FluorImager.

Methylation analysis. The methylation status of the Smad4 promoter was analyzed by methylation-specific PCR (MSP) (10) using the CpGenome DNA Modification Kit (Intergen Co., Purchase, NY). The fragment selected for this analysis was a CG-rich region, including $550 \mu \mathrm{l}$ of freshly prepared non-coded sodium bisulfite mixture (Intergen Co.). These solutions were incubated at $50^{\circ} \mathrm{C}$ for $16 \mathrm{~h}$. In bisulfite modification, all unmethylated cytosines are deaminated and converted to uracils, while the 5'-methylcytosines remain unaltered. The DNA samples were purified by ethanol precipitation and resuspended in $25 \mu 1$ of TE (10 mM Tris/ 
Table I. List of primer and probe sequences used in the real-time reverse transcriptase-polymerase chain reaction of the indicated genes.

\begin{tabular}{lccc}
\hline Gene & Sense primer sequence (5'-3') & Antisense primer sequence (5'-3') & Probe sequence (5'-3') \\
\hline Smad4 & aaaacggccatcttcagcac & aggccagtaatgtccggga & acccgcctatgccgcccc \\
GAPDH & gaaggtgaaggtcggagtc & gaagatggtgatgggatttc & caagcttcccgttctcagcc \\
\hline
\end{tabular}

${ }^{\mathrm{a}}$ Glyceraldehyde-3-phosphate dehydrogenase.

Table II. List of primer sequences for amplification of each exon of each gene.

\begin{tabular}{|c|c|c|}
\hline Gene & Sense primer sequence $\left(5^{\prime}-3^{\prime}\right)$ & Antisense primer sequence $\left(5^{\prime}-3^{\prime}\right)$ \\
\hline \multicolumn{3}{|l|}{ Smad4 } \\
\hline Exon 1-1 & tcagaaattggagacatattt & tcttttttctcettcagcttc \\
\hline Exon 1-2 & agtgaaacatttgcaaaaagag & gtttttaaatctgccaccatag \\
\hline Exon 2 & aaagtgtcttgcataatatgac & ttcttaggatgaaacaaactac \\
\hline Exon 3 & ctttcattgtaatgattaatgtttc & aagagaaagtagtaagaaacag \\
\hline Exon 4-1 & gattttaggtgttattatattacttg & ctctgtcgatgcacgattac \\
\hline Exon 4-2 & ttgtccactgaaggacattc & gctgactacatctgattctag \\
\hline Exon 5 & cataagatgacatctatgaatg & gcttttataaaggetgcctac \\
\hline Exon 6 & taaaagcaaattaacccatgtg & cccttacaacaaaaacaagag \\
\hline Exon 7 & tgaaagttttagcattagacaac & cgtttcaatcaccactaaatc \\
\hline Exon 8 & tttctcatgggaggatgttc & caattttttaaagtaacttactgac \\
\hline Exon 9-1 & tattaagcatgctatacaatctg & ctgtctaagtagtaactctg \\
\hline Exon 9-2 & caaaggtgtgcagttggaatg & cttccacccagatttcaattc \\
\hline Exon 10 & gaattttctttatgaactcatag & tttaaaaaagaatgaaaagcatac \\
\hline Exon 11-1 & ctgatgtcttccaaactcttttctg & ggcatggtatgaagtcattcgtc \\
\hline Exon 11-2 & ctgatgtcttccaaactcttttctg & tgtattttgtagtccaccatc \\
\hline \multicolumn{3}{|l|}{$T G F-\beta R I I^{\mathrm{a}}$} \\
\hline Exon 3 & tccaatgaatctcttcactc & cccacacccttaagagaaga \\
\hline Exon 7 & ccaactcatggtgtccetttg & tctttggacatgeccagcetg \\
\hline
\end{tabular}

aTransforming growth factor- $\beta$ receptor type II.

$0.1 \mathrm{mM}$ EDTA, pH 7.5). PCR amplification was performed using methylation-specific primers that had been designed to distinguish methylated from unmethylated DNA. One primer set (forward 5'-AGTGAGAGAGGT TTTTTGTTGTAGG-3' and reverse 5'-CCACCACCACCA TCATC-3') was designed to anneal to unmethylated DNA that had undergone a chemical modification. A second primer set (forward 5'-GTTGAGGAG GGGCGGTTTGG-3' and reverse 5'-CCCTCCCAAAAAATT CC-3') was designed to anneal to methylated DNA that had undergone a chemical modification. A third primer set (forward 5'-TGCTCAGTGGCTTCTCG-3' and reverse 5'-TAGGGG AGAGCAGGAAG-3') was designed to anneal to unmodified DNA. The PCR reaction mixture consisted of 10X PCR buffer, $2.5 \mathrm{mM}$ dNTPs, $10 \mathrm{pmol}$ of each primer, $1.25 \mathrm{U}$ of AmpliTaq Gold and $2 \mathrm{ng}$ of template DNA in a final volume of $25 \mu \mathrm{l}$. PCR was performed as follows: denaturation at $95^{\circ} \mathrm{C}$ for $12 \mathrm{~min}$, denaturation at $95^{\circ} \mathrm{C}$ for $30 \mathrm{sec}$, annealing at $60^{\circ} \mathrm{C}$ for
$45 \mathrm{sec}$ and extension at $72^{\circ} \mathrm{C}$ for $45 \mathrm{sec}$ for 35 cycles. A total of $10 \mu \mathrm{l}$ of each allele-specific PCR sample was mixed with $2 \mu \mathrm{l}$ of loading dye and loaded on a $1.2 \%$ agarose gel. The gel was stained with ethidium bromide.

Sequencing analysis. When bands of methylated DNA were detected in the methylation analysis, they were excised from the gels, purified with Geneclean II Kit (Bio 101, Vista, CA) and ligated into the pPCR Script Amp SK(+) cloning vector (Stratagene, La Jolla, CA). Subsequently, 8-10 independent clones were sequenced by fluorescent automated sequencing (Perkin Elmer/Applied Biosystems) (4).

Cloning and reporter assays of the promoter region of the Smad4 gene. Smad4 promoter fragments from normal human lung DNA were generated with Advantage GC 2 PCR (Clontech, Palo Alto, CA). The primer sequences were 
Table III. Differential expression of genes in pulmonary fibrosis and lung carcinoma tissues in cDNA array analysis.

\begin{tabular}{|c|c|c|c|c|c|c|}
\hline Gene name & Classification & Patient 1 & Patient 2 & Patient 3 & Patient 4 & Patient 5 \\
\hline Smad4 & Regulatory transcription factors & $\mathrm{IP}>\mathrm{Ca}^{\mathrm{a}}$ & $\mathrm{IP}>\mathrm{Ca}^{\mathrm{a}}$ & $\mathrm{IP}=\mathrm{Ca}^{\mathrm{b}}$ & $\mathrm{IP}>\mathrm{Ca}^{\mathrm{a}}$ & $\mathrm{IP}=\mathrm{Ca}^{\mathrm{b}}$ \\
\hline$p 21$ & Cell cycle protein & $\mathrm{IP}>\mathrm{Ca}^{\mathrm{a}}$ & $\mathrm{IP}>\mathrm{Ca}^{\mathrm{a}}$ & $\mathrm{IP}=\mathrm{Ca}^{\mathrm{b}}$ & $\mathrm{IP}=\mathrm{Ca}^{\mathrm{b}}$ & $\mathrm{IP}=\mathrm{Ca}^{\mathrm{b}}$ \\
\hline Metallothionein & Metabolic enzyme & $\mathrm{IP}=\mathrm{Ca}^{\mathrm{b}}$ & $\mathrm{IP}>\mathrm{Ca}^{\mathrm{a}}$ & $\mathrm{IP}=\mathrm{Ca}^{\mathrm{b}}$ & $\mathrm{IP}=\mathrm{Ca}^{\mathrm{b}}$ & $\mathrm{IP}>\mathrm{Ca}^{\mathrm{a}}$ \\
\hline$M M P-7$ & Signaling intermediates & $\mathrm{IP}=\mathrm{Ca}^{\mathrm{b}}$ & $\mathrm{IP}>\mathrm{Ca}^{\mathrm{a}}$ & $\mathrm{IP}=\mathrm{Ca}^{\mathrm{b}}$ & $\mathrm{IP}=\mathrm{Ca}^{\mathrm{b}}$ & $\mathrm{IP}>\mathrm{Ca}^{\mathrm{a}}$ \\
\hline TIMP-1 & Signaling intermediates & $\mathrm{IP}=\mathrm{Ca}^{\mathrm{b}}$ & $\mathrm{IP}>\mathrm{Ca}^{\mathrm{a}}$ & $\mathrm{IP}=\mathrm{Ca}^{\mathrm{b}}$ & $\mathrm{IP}>\mathrm{Ca}^{\mathrm{a}}$ & $\mathrm{IP}=\mathrm{Ca}^{\mathrm{b}}$ \\
\hline
\end{tabular}

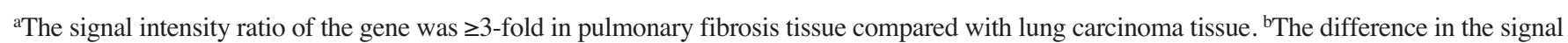
intensity ratio of the gene between pulmonary fibrosis tissue and lung carcinoma tissue was <3-fold. MMP-7, matrix metalloproteinase-7; TIMP-1, tissue inhibitor of matrix metalloproteinase.

Table IV. Relative expression levels of Smad4 using real-time reverse transcriptase-polymerase chain reaction.

\begin{tabular}{c}
$\begin{array}{c}\text { Relative expression } \\
\text { levels of Smad4 } 4^{a}\end{array}$ \\
\hline
\end{tabular}

\section{Normal tracheal cell \\ Normal human lung}

1

Tumors from lung cancer/IPF patients ${ }^{\mathrm{b}}$

$0.08 \pm 0.07$

Tumors from lung cancer patients without IPFc

$2.45 \pm 2.20$

Cell lines ${ }^{\mathrm{d}}$

$0.58 \pm 0.41$

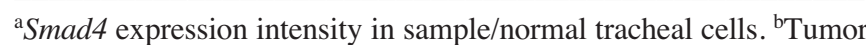
samples from eight lung cancer patients with idiopathic pulmonary fibrosis (IPF). ${ }^{c}$ Tumor samples from four lung cancer patients without

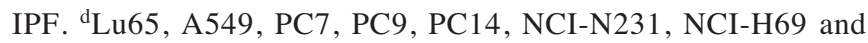
$\mathrm{Lu} 135$. Data are expressed as the mean $\pm \mathrm{SD}$. The relative expression level of Smad4 was significantly lower in tumors from lung cancer/ IPF patients than in lung cancer cell lines $(\mathrm{p}<0.01$, Mann-Whitney U test).

designed on the basis of methylation analysis with the $M l u \mathrm{I}$ or BgIII sites. Forward primer (5'-ACTACGCGTATGCTCA GTGGCTTCTCG-3') and reverse primers (1 5'-GTAAGA TCTTCGCCCTCCCAGAGGATTC-3' and 2 5'-GTAAGA TCTACATGGCGCGGTTACCTG-3') were designed to amplify the promoter region of Smad4 with (reverse 1) or without (reverse 2) the sequence including the methylated region from the methylation analysis. First, PCR products including the promoter region of Smad4 were subcloned into pPCR-Script Amp SK(+) cloning vector. Second, luciferase plasmids containing the Smad4 promoter region were generated by cloning PCR products into the MluI and BgIII sites of pGL3-Basic Vector (Promega, Madison, WI). The luciferase plasmids with or without the Smad4 promoter regions and pRL-TK vector (Promega) were co-transfected into A549 cells using the CalPhos ${ }^{\mathrm{TM}}$ Mammalian Transfection Kit (Clontech). Protein extracts were prepared, and luciferase activity was measured by the Dual-Luciferase Reporter Assay Systems (Promega).

\section{Results}

cDNA array analysis. We used cDNA array screening to identify genes differentially expressed in lung cancer and IPF tissues from lung cancer/IPF patients. A sufficient amount of total RNA for the cDNA array analysis could be extracted from only five of the eight patients. Comparison of chemifluorescent intensities produced by the lung cancer and IPF samples showed varying expression patterns, but Smad4 was down-regulated in three of the five patients. Metallothionein, p21, MMP-7 (matrix metalloproteinase-7) and TIMP-1 (Tissue inhibitor of matrix metalloproteinase) were down-regulated in two of five patients (Table III). TGF- $\beta, T G F-\beta R$ - II and other Smads were equally expressed between the pairs of lung cancer and IPF sample series.

Real-time quantitative reverse transcriptase-polymerase chain reaction. To confirm the differential expression of Smad4, we performed real-time quantitative RT-PCR (Table IV). Adequate amounts of total RNA for use in real-time RT-PCR from both lung cancer and IPF samples were available from six of eight lung cancer/IPF patients. In the remaining two patients, total RNA could only be extracted from the lung cancer tissue. We compared Smad4 expression in patient lung cancers, normal tracheal cells and normal human lung tissue (BD Biosciences, Clontech, CA). All eight lung cancer/IPF patients showed down-regulation of Smad4 expression in lung cancer compared to normal tracheal cells and normal human lung. There was no significant difference in Smad4 expression in normal tracheal cells and normal human lung. Moreover, we compared Smad4 expression in lung cancer/IPF and lung cancer without IPF patients. The relative expression level of Smad4 in tumors from lung cancer/IPF patients $(0.08 \pm 0.07)$ was significantly lower than in tumors from lung cancer without IPF patients $(2.45 \pm 2.20)$ ( $\mathrm{p}=0.0065$, Mann-Whitney $\mathrm{U}$ test). The relative expression level of Smad4 was also significantly lower in tumors from lung cancer/IPF patients than in the lung cancer cell lines $(0.58 \pm 0.41)(p=0.0053$, Mann-Whitney U test). Four of the six lung cancer/IPF patients showed down-regulation of Smad4 expression in lung cancer tissue compared to IPF tissue; the other two patients showed almost equal levels of Smad4 expression between the tissues. 


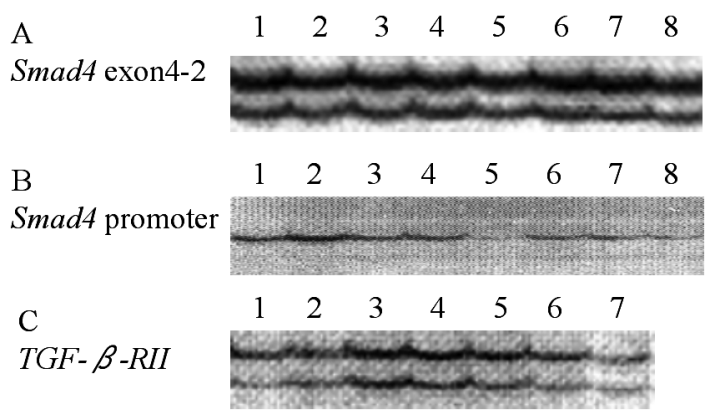

Figure 1. Representative results of PCR-SSCP analysis. (A) Smad4 exon 4-2. (B) Smad4 promoter and (C) TGF- $\beta$ RII (transforming growth factor- $\beta$ receptor type II). No abnormal mobility shift is present in any panels. Numbers on the panels indicate patient number.

Polymerase chain reaction-single strand conformation polymorphism analysis. One possible mechanism of the downregulation of Smad4 expression is the inactivation of Smad4 by intragenic mutation. We performed PCR-SSCP analysis using 15 primer sets with intronic sequences designed to amplify Smad4 exons 1-11 and one primer set designed to amplify the Smad4 promoter. Exons 1-11 of the Smad4 gene and the Smad4 promoter were successfully amplified by PCR in eight of the lung cancer samples obtained from lung cancer/IPF patients. No SSCP variants were detected (Fig. 1A and B). Additionally, PCR-SSCP analysis was performed on the mutational hot spots of the $T G F-\beta R$ RII gene in the same specimens, but SSCP variants were not detected (Fig. 1C).

Methylation analysis. An alternative mechanism of transcriptional repression is the hypermethylation of $\mathrm{CpG}$ islands in the Smad4 promoter. To investigate the methylation status of the Smad4 promoter, MSP was performed on tumor DNA obtained from eight lung cancer/IPF patients. Among the eight patients, the methylated band of the Smad4 gene was observed in samples obtained from the two patients whose Smad4 expression was down-regulated in real-time quantitative RT-PCR analysis. The DNA sequences of the methylated and unmethylated bands were confirmed, and the representative results are shown in Fig. 2. In two cases, similar methylated regions in the Smad4 promoter were observed.

Smad4 promoter reporter assays. To verify the biological significance of the hypermethylation of the Smad4 promoter observed in methylation analysis, two Smad4 promoter fragments from normal human lung DNA were generated with Advantage GC 2 PCR. The PCR primer pairs were designed to amplify the Smad4 promoter with (promoter fragment 1) or without (promoter fragment 2) a 125 base pair including the methylated region of the Smad4 promoter observed in the methylation analysis (Fig. 3). After subcloning, luciferase plasmids containing the Smad4 promoter regions were generated by cloning PCR products into Mlu 1 and $B g 1 \mathrm{II}$ sites of pGL3Basic Vector. Luciferase assays were performed using the luciferase vector with or without Smad4 promoters. The promoter activity/TK promoter activity ratio was significantly higher in cells transfected with the vector containing promoter fragment $1(0.057 \pm 0.034)$ (11 clones) than in cells transfected
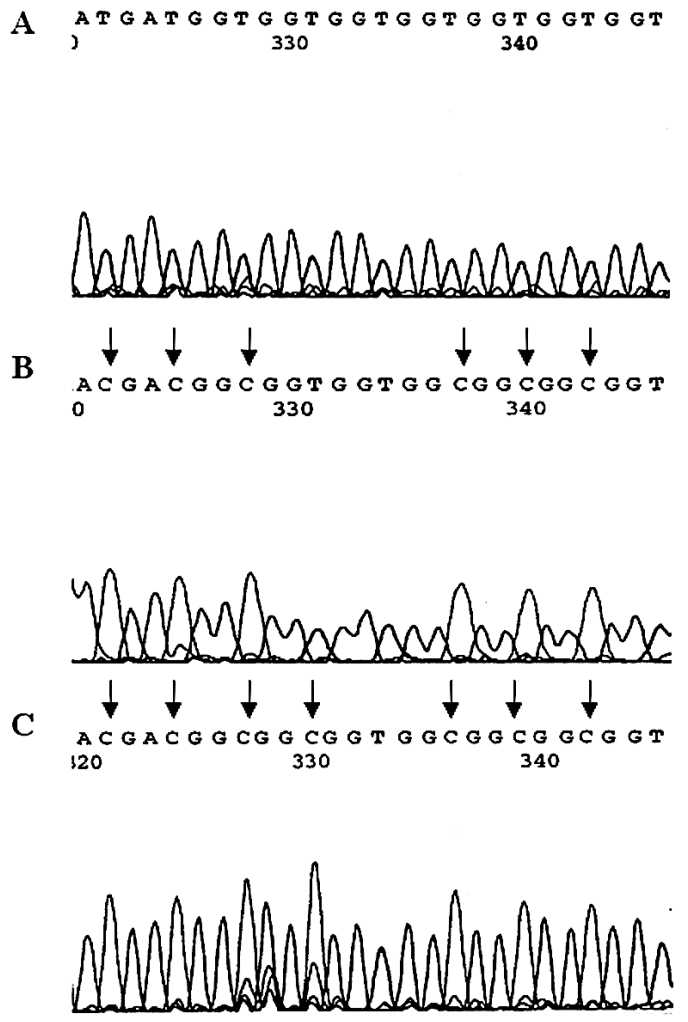

Figure 2. DNA sequence analysis of the MSP bands in lung cancers obtained from lung cancer/IPF patients. (A) Patient no. 3, unmethylated sequence. (B) patient no. 4, methylated sequence. (C) patient no. 8, methylated sequence. Arrows indicate methylated cytosines.

with the vector containing promoter fragment $2(0.016 \pm 0.005)$ (9 clones) ( $\mathrm{p}=0.002$, Mann-Whitney U test) (Fig. 4). These data indicate the presence of enhanced promoter activity within the region including the methylated sequence observed in the methylation analysis.

\section{Discussion}

The incidence of lung cancer is much higher in patients with IPF than in the general population $(1,2)$. Predisposing factors in the development of lung cancer in IPF include squamous metaplasia, atypical epithelial cell proliferation with nuclear and cytoplasmic changes, and cuboidal and columnar epithelium in the terminal bronchioles (11). We previously reported that allelic loss of the FHIT gene was found in these epithelial regions and may be involved in carcinogenesis in the peripheral lung of patients with IPF (3).

To investigate the genetic events involved in the transformation of the epithelial region in patients with IPF, we performed cDNA array analysis to screen genes that were differentially expressed in lung cancer compared with IPF (5). Of the five patients examined, three showed down-regulation of the Smad4 gene in lung cancer tissue compared with IPF tissue. Problems associated with global analysis include cross hybridization, selection of the control and the definition of significant differences. In this study, all eight lung cancer/IPF patients showed down-regulation of Smad4 expression in lung cancer tissue compared to normal tracheal cells and normal 
GCCAAACCCTGAAATTACCCGGATGTGGTCCCCGCGCGCGCATGCTCAGTGGCTTCTCGACAA

GTTGGCAGCAACAACACGGCCCTGGTCGTCGTCGCCGCTGCGGTAACGGAGCGGTTTGGGTG

GCGGAGCCTGCGTTCGCGCCTTCCCGCTCTCCTCGGGAGGCCCTTCCTGCTCTCCCCTAGGCT

CCGCGGCCGCCCAGGGGGTGGGAGCGGGTGAGGGGAGCCAGGCGCCCAGCGAGAGAGGCC

CCCCGCCGCAGGGCGGCCCGGGAGCTCGAGGCGGTCCGGCCCGCGCGGGCAGCGGCGCGGC

GCTGAGGAGGGGCGGCCTGGCCGGGACGCCTCGGGGCGGGGGCCGAGGAGCTCTCCGGGCC

GCCGGGGAAAGCTACGGGCCCGGTGCGTCCGCGGACCAGCAGCGCGGGAGAGCGGACTCCC

$1-$ reverse2

CTCGCCACCGCCCGAGCCCAGGTAACCGCGCCATGTCCCCTCCCCTTCCCCCGGCCGGGCCCG

CGCACCCCGCCTGTGGCTTCCCCGCCCCGGGGCGGGCTCCCGACGACGGCGGEGGCGGEGG므

GGEGGCTGGGAGCGCGCGGAATCCTCTGGGAGGGCGACCGCGGCGGCCTGACGAGCCGGGCC

GGGCGGGCCGGCTGAATGCCGGGCGGCGGTGCCTCGCGTCCCTCGGGCCCCCAGCTCCGCTTG

CAGCTCGTGGGAGAATCAA

Figure 3. The Smad4 promoter region was studied for methylation analysis and luciferase assay. Primers for luciferase assays were designed to amplify the promoter regions of Smad4 with (promoter fragment 1) or without (promoter fragment 2) the methylated region on DNA sequence analysis of the MSP bands (Fig. 2). Primers for promoter fragment 1 , forward and reverse 1; primers for promoter fragment 2 , forward and reverse 2 . Underlined $\mathrm{C}$ shows methylated cytosine on DNA sequence analysis of the MSP bands.

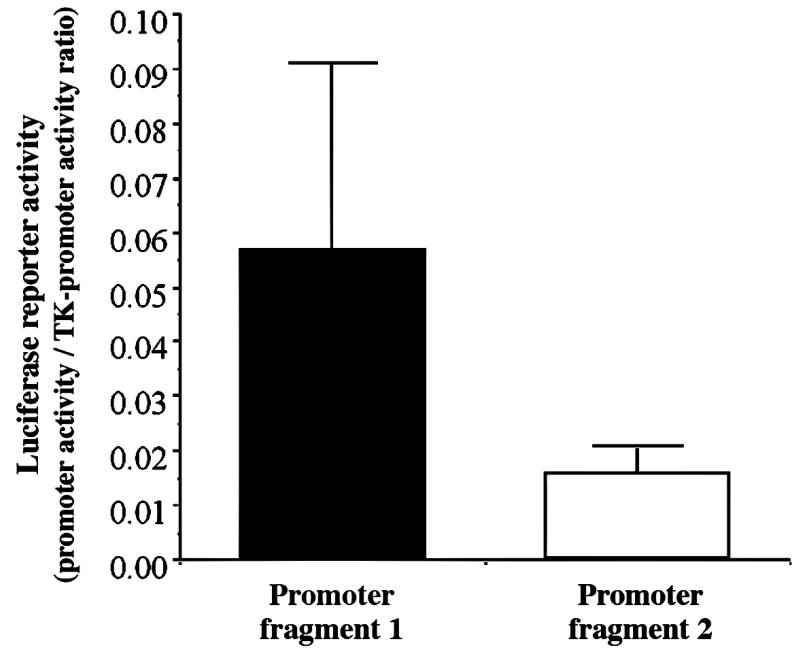

Figure 4. Luciferase assay with Smad4 promoter reporters using normal human lung DNA. The promoter activity/TK promoter activity ratio was significantly higher in promoter fragment $1(0.057 \pm 0.034)$ than in promoter fragment $2(0.016 \pm 0.005)(\mathrm{p}=0.002$, Mann Whitney $\mathrm{U}$ test $)$.

human lung tissue. Relative expression of the Smad4 gene was significantly lower in tumors from lung cancer/IPF patients than in tumors from lung cancer without IPF patients or in lung cancer cell lines. These data imply that down-regulation of the Smad4 gene may be involved in the development of lung cancer in pulmonary fibrosis.

It has also been demonstrated that TGF- $\beta$ is expressed in increased quantities in the lung tissue of patients with IPF $(12,13)$. TGF- $\beta$ is a multifunctional cytokine that inhibits epithelial cell proliferation, and there is a strong correlation between malignant progression and loss of sensitivity to the antiproliferative effects of TGF- $\beta$. Tumor cells often escape the antiproliferative effects of TGF- $\beta$ by the mutational inactivation or dysregulated expression of components in the TGF-ß signal pathway (14). Loss of the growth inhibitory response to TGF- $\beta$ may therefore be crucial in promoting tumor development in the lungs of IPF patients, where TGF- $\beta$ is highly expressed.

Biological signals for TGF- $\beta$ are transducted through heteromeric complexes of two transmembrane serine/threonine kinase receptors (TGF- $\beta$ RI and TGF- $\beta$ RII), then propagated to a family of Smads. Smads can be subdivided into three classes based on their functional properties: receptor-regulated Smads (Smads 1, 2, 3, 5 and 8), common Smads (Smad4) and antagonistic Smads (Smads 6 and 7) $(15,16)$. Smad4 was first identified as a candidate tumor suppressor gene in pancreatic carcinomas, in which nearly $40 \%$ of patients had lost or had an inactivated version of Smad4, and was initially known as Deleted in pancreatic carcinoma locus 4 (DPC4) (17). Smad4 acts as a convergent node in the Smad pathways, downstream of TGF- $ß$ superfamily receptors. Smad4 alterations are largely restricted to tumors of the pancreas and gastrointestinal tract $(17,18)$, with a much lower frequency in those of the lung $(19,20)$. To determine the mechanism of down-regulation of Smad4 expression in lung carcinoma tissues in patients with IPF, we performed PCR-SSCP analysis. No SSCP variants were found in any exons of Smad4 or the Smad4 promoter in tumor samples from eight lung cancer/IPF patients. Therefore, we performed MSP to analyze the methylation status of the promoter regions of the Smad4 gene. Aberrant methylation of 
normally unmethylated $\mathrm{CpG}$ islands has been associated with transcriptional inactivation of defined tumor suppressor genes in human cancers $(21,22)$. Methylation of gene promoters results in chromatin condensation, limiting accessibility of transcription factors to the DNA (23). In the present study, hypermethylation of the Smad4 promoter was identified in two of eight $(25.0 \%)$ patients who showed reduced Smad4 expression in lung cancer.

To verify the biological significance of the hypermethylation of the Smad4 promoter observed in methylation analysis, we studied the difference in Smad4 promoter activity with or without the methylated region using reporter constructs. The decreased promoter activity observed when a 125 base pair including the methylated region was deleted demonstrated the significance of the region and indicated the potential involvement of DNA methylation in reduced expression of the $S m a d 4$ gene in lung cancer/IPF patients.

$T G F-\beta, T G F-\beta R I I$ and other Smads were equally expressed between the pairs of lung cancer and IPF samples. It was reported that a mutation in exon 3 of the $T G F-\beta$ RII gene was observed, although at a low incidence, in hyperplastic lesions of alveolar lining epithelial cells in IPF (24). This is a predisposing factor in the development of lung cancer in IPF patients. Mutations of the TGF- $\beta$ RII gene have also been found in various tumors, but incidences of code-altering mutations are rare $(25,26)$. If mutation of the $T G F-\beta$ RII gene occurs in the pre-cancerous lesions of IPF, it would be identified in lung cancers developed from IPF fibrotic lesions. However, a mutation in exon 3 of the TGF- $\beta$ RII gene was not detected in any of the eight patients examined in our study.

Our data suggests that loss of the growth inhibitory response to TGF- $\beta$ signaling may be crucial in promoting tumor development in patients with IPF, and that hypermethylation of the Smad4 promoter region may be one mechanism by which this occurs. Other possible mechanisms of Smad4 down-regulation include alterations in chromatin structure due to histone deacetylation (27). Sporadic lung cancer was also reported to show frequent loss of sensitivity to the antiproliferative effects of TGF- $\beta$ (28). The mechanism of resistance was reported to be reduced expression of the $T G F-\beta R I I$ gene through hypermethylation of the $T G F-\beta R I I$ gene promoter region and histone deacetylation (27). Inactivation of Smad4, which acts as a convergent node in the Smad pathways downstream of TGF- $\beta$ superfamily receptors, may play a specific role in the process of pulmonary carcinogenesis in IPF.

In summary, our study demonstrated that down-regulation of the Smad4 gene may be involved in lung carcinogenesis in patients with IPF. Further investigation in this area may aid in the development of novel preventative measures or modes of treatment for patients with lung cancer and IPF through the regulation of Smad4 expression. Aberrant DNA methylation of the Smad4 promoter region may be one possible therapeutic target because of differences between lung cancer and IPF lung tissue.

\section{Acknowledgements}

This study was supported by a Grant-in-Aid from the Japan Society for the Promotion of Science (to A.G. and S.K.).

\section{References}

1. Panos RJ, Mortenson RL, Niccoli SA and King TE Jr: Clinical deterioration in patients with idiopathic pulmonary fibrosis: causes and assessment. Am J Med 88: 396-404, 1990.

2. Hubbard R, Venn A, Lewis S and Britton J: Lung cancer and cryptogenic fibrosing alveolitis. A population-based cohort study. Am J Respir Crit Care Med 61: 5-8, 2000.

3. Uematsu K, Yoshimura A, Gemma A, Mochimaru H, Hosoya Y, Kunugi S, Matsuda K, Seike M, Kurimoto F, Takenaka K, Koizumi K, Fukuda Y, Tanaka S, Chin K, Jablons DM and Kudoh S: Aberrations in the Fragile histidine triad (FHIT) gene in idiopathic pulmonary fibrosis. Cancer Res 61: 8527-8532, 2001.

4. Gemma A, Hagiwara K, Ke Y, Burke LM, Kahn MA, Nagashima M, Bennett WP and Harris CC: FHIT mutations in human primary gastric cancer. Cancer Res 57: 1435-1437, 1997.

5. Gemma A, Takenaka K, Hosoya Y, Matuda K, Seike M, Kurimoto F, Ono Y, Uematsu K, Takeda Y, Hibino S, Yoshimura A, Shibuya M and Kudoh S: Altered expression of several genes in highly metastatic subpopulations of a human pulmonary adenocarcinoma cell line. Eur J Cancer 37: 1554-1561, 2001.

6. Wang D, Kanuma T, Mizunuma H, Takama F, Ibuki Y, Wake N, Mogi A, Shitara Y and Takenoshita S: Analysis of specific gene mutations in the transforming growth factor- $\beta$ signal transduction pathway in human ovarian cancer. Cancer Res 60: 4507-4512, 2000.

7. Hahn SA, Bartsch D, Schroers A, Galehdari H, Becker M, Ramaswamy A, Schwarte Waldhoff I, Maschek H and Schmiegel W: Mutations of the DPC/Smad4 gene in biliary tract carcinoma. Cancer Res 58: 1124-1126, 1998.

8. Bartsch D, Barth P, Bastian D, Ramaswamy A, Gerdes B, Chaloupka B, Deiss Y, Simon B and Schudy A: Higher frequency of DPC4/Smad4 alterations in primary pancreatic adenocarcinomas. Cancer Lett 139: 43-49, 1999.

9. Roth S, Laiho P, Salovaara R, Launonen V and Aaltonen LA: No Smad4 hypermethylation in colorectal cancer. Br J Cancer 83: 1015-1019, 2000

10. Herman JG, Graff JR, Myohanen S, Nelkin BD and Baylin SB: Methylation-specific PCR: a novel PCR assay for methylation status of CpG islands. Proc Natl Acad Sci USA 93: 9821-9826, 1996.

11. Haddad R and Massaro D: Idiopathic diffuse interstitial pulmonary fibrosis (fibrosing alveolitis), atypical epithelial proliferation and lung cancer. Am J Med 45: 211-219, 1968.

12. Khalil N, O'Connor RN, Unruh P, Warren A, Kemp O, Bereznay K, Flanders KC and Green AH: Increased production and immunohistochemical localization of transforming growth factor-beta (TGF- $\beta$ ) in idiopathic pulmonary fibrosis. Am J Respir Cell Mol Biol 5: 155-162, 1990.

13. Khalil N, O'Connor RN, Flanders KC and Unruh H: TGF-ß, but not TGF- $\beta 2$ or TGF- $\beta 3$, is differentially present in epithelial cells of advanced pulmonary fibrosis: An immunohistochemical study. Am J Respir Cell Mol Biol 14: 131-138, 1996.

14. De Caestecker MP, Piek E and Roberts AB: Role of transforming growth factor- $\beta$ signaling in cancer. J Natl Cancer Inst 92: 1388-1402, 2000.

15. Attisano L and Wrana JL: Smads as transcriptional co-modulators. Curr Opin Cell Biol 12: 235-243, 2000.

16. Massagué $\mathrm{J}$ and Wotton D: Transcriptional control by the TGF- $B /$ Smad signaling system. EMBO J 19: 1745-1754, 2000.

17. Hahn SA, Schutte M, Hoque AT, Moskaluk CA, Da Costa LT, Rozenblum E, Weinstein CL, Fisher A, Yeo CJ, Hruban RH and Kern SE: DPC4, a candidate tumor suppressor gene at human chromosome 18q21.1. Science 271: 350-353, 1996.

18. Thiagalingam S, Lengauer C, Leach FS, Schutte M, Hahn SA and Overhauser J: Evaluation of candidate tumor suppressor genes on chromosome 18 in colorectal cancers. Nat Genet 13: 343-346, 1996.

19. Nagatake M, Takagi Y, Osada H, Uchida K, Mitsudomi T, Saji S, Shimokawa K and Takahashi T: Somatic in vivo alterations of the DPC4 gene at 18q21 in human lung cancers. Cancer Res 56: 2718-2720, 1996.

20. Schutte M, Hruban RM, Hedrick L, Cho KR, Nadasdy GM, Weinstein CL, Bova GS, Isaacs WB, Cairns P, Nawroz H, Sidransky D, Casero RA Jr, Meltzer PS, Hahn SA and Kern SE: DPC4 gene in various tumor types. Cancer Res 56: 2527-2530, 1996.

21. Herman JG, Latif F, Weng Y, Lerman MI, Zbar B, Liu S, Samid D, Duan DR, Gnarra JR, Linehan WM and Baylin SB: Silencing of the VHL tumor-suppressor gene by DNA methylation in renal carcinoma. Proc Natl Acad Sci USA 91: 9700-9704, 1994. 
22. Merlo A, Herman JG, Mao L, Lee DJ, Gabrielson E, Burger PC, Baylin SB and Sidransky D: 5' CpG island methylation is associated with transcriptional silencing of the tumour suppressor p16/CDKN2/MST1 in human cancers. Nat Med 1: 686-692, 1995.

23. Jones PL and Wolffe AP: Relationships between chromatin organization and DNA methylation in determining gene expression. Semin Cancer Biol 9: 339-347, 1999.

24. Mori M, Kida H, Morishita H, Goya S, Matsuoka H, Arai T, Osaki T, Tachibana I, Yamamoto S, Sakatani M, Ito M, Ogura T and Hayashi S: Microsatellite instability in transforming growth factor- $\beta 1$ type II receptor gene in alveolar lining epithelial cells of idiopathic pulmonary fibrosis. Am J Respir Cell Mol Biol 24: 398-404, 2001

25. Parsons R, Myeroff L, Liu B, Wilson JKV, Markowitz S, Kinzler KW and Vogelstein B: Microsatellite instability and mutations of the transforming growth factor $\beta$ type II receptor gene in colorectal cancer. Cancer Res 55: 5548-5550, 1995.
26. Takenoshita S, Hagiwara K, Gemma A, Nagashima M, Ryberg D, Lindstedt BA, Bennet WP, Haugen A and Haris CC: Absence of mutations in the transformation growth factor- $\beta$ type II receptor in sporadic lung cancers with microsatellite instability and rare H-ras1 alleles. Carcinogenesis 18: 1427-1429, 1997.

27. Osada H, Tatematsu Y, Masuda A, Saito T, Sugiyama M, Yanagisawa $\mathrm{K}$ and Takahashi T: Heterogeneous transforming growth factor (TGF)- $\beta$ unresponsiveness and loss of $T G F-\beta$ receptor type-II expression caused by histone deacetylation in lung cancer cell lines. Cancer Res 61: 8331-8339, 2001.

28. Gold LI: The role of transforming growth factor- $\beta$ (TGF- $\beta$ ) in human cancer. Crit Rev Oncog 10: 303-360, 1999. 